\title{
Ossified materialism: introduction to the special volume on absolute reductions in materials throughput and emissions
}

Lewis Akenji ${ }^{1}$, Magnus Bengtsson ${ }^{2}$, Raimund Bleischwitz ${ }^{3}$, Arnold Tukker ${ }^{4}$, Heinz Schandl ${ }^{5}$,

${ }^{1}$ Corresponding author: Institute for Global Environmental Strategies (IGES), 2108-11

Kamiyamaguchi, Hayama, Kanagawa, 240-0115 Japan. Tel: +81-46-826-9594 Fax: +81-

46-855-3709. Email: akenji@live.com

${ }^{2}$ Institute for Global Environmental Strategies (IGES), 2108-11 Kamiyamaguchi, Hayama, Kanagawa, 240-0115 Japan. Tel: +81-46-855-3843 Fax: +81-46-855-3709. Email:

bengtsson@iges.or.jp

${ }^{3}$ BHP Billiton Chair in Sustainable Global Resources, University College London (UCL) Deputy Director, UCL Institute for Sustainable Resources

Central House, 14 Upper Woburn Place, London, WC1H 0NN, UK

Email: r.bleischwitz@ucl.ac.uk; phone: +44 (0) 203108 9207; mobile: +44 (0) 7943521084

${ }^{4}$ Scientific director and head of the department of Industrial Ecology

Institute of Environmental Sciences (CML), Leiden University, Einsteinweg 2, Leiden

Senior Researcher, TNO, Van Mourik Broekmanweg 6, Delft, NL

Email: tukker@cml.leidenuniv.nl; tel.+31 71 5275632/5615; mob.+31 651980344

${ }^{5}$ Commonwealth Scientific and Industrial Research Organisation (CSIRO), Black Mountain

Laboratories, Clunies Ross Street, Acton, 2601 ACT, Canberra, Australia. Tel: +61 26246

4345. Email: heinz.schandl@csiro.au

\begin{abstract}
Drawing from papers in this special volume (SV), this introductory paper on absolute reductions argues that the magnitude, scope and urgency of the sustainability challenge require a drastic change in global civilisation, including a radical transformation of the institutional arrangements and socio-technical systems that facilitate the pursuit of wellbeing. The authors of this paper identify four main challenges to absolute reductions, including: the resource-intensive conventional template for development, macroeconomic structures and trade policies creating burden-shifting and inequality, a resource-efficiency improvements fallacy, and the dominant consumerist culture and lifestyles. The paper demonstrates the complexity of translating planetary boundaries into boundaries for resource use and targets for absolute reductions, proposing a practical approach starting with defining footprints for water, land and materials, and then proceeding to set resource boundaries. In seeking potential solutions, the paper highlights research addressing materials and product substitution, ecological fiscal reform with measures such as carbon taxation, sustainable lifestyles, design for sustainability, eco-innovation, and management of power dynamics in the production-consumption system. We then propose six domains in a research agenda for future research. These include: moving from niches and demonstration projects to broader norms; addressing reductions targets and indicators to guide policy and action; including policy design reflecting complexities such as time-lags, the resource nexus, and positive feedback loops; global resource governance; and convergence pathways between overconsuming and under-consuming societies. These areas will provide the science that will
\end{abstract}


inform policy and business decisions and guide the engagement of practitioners to work towards sustainability transitions to equitable, sustainable, post-fossil carbon societies.

Keywords: absolute reductions, social change, natural resource consumption, planetary boundaries, natural resource targets, sustainability science

\section{Introduction: the magnitude, scope and urgency of the sustainability challenges}

This Special Volume (SV) on Absolute Reductions ${ }^{1}$ is a result of an exploratory project which generates new knowledge for a societal transformation towards a sustainable civilisation, aiming for a global society that operates and thrives within its ecological limits. The choice of the words "Absolute" and "Reductions" are deliberately provocative, reflecting the growing body of scientific assessments (IPCC, 2014; Rothman et al., 2009; UNEP, 2007, 2012; Millennium Ecosystem Assessment, 2005) demonstrating that current approaches to sustainability, characterised by efficiency improvements, relative decoupling, and green consumerism alone are insufficient. Sustainability measures are being determined by whims of the current market economy (Simms, Johnson, \& Chowla, 2010; Thomas, 2009) and tend to ignore the real prospects of an ecological collapse that threatens the wellbeing of vulnerable groups and ultimately global society. When government policy makers have addressed unsustainability, it has tended to rely on technology, which has been shown to be an insufficient remedy on its own, or on consumer scapegoatism (Akenji, 2014; Eriksson, 2004), by urging consumers to buy green products rather than by addressing the fundamental problems of the current systems of production and consumption. By avoiding addressing the environmental consequences of modern systems of production and consumption the required fundamental systemic changes are postponed and a social and economic order that creates environmental disruption, social exclusion and economic inequity is perpetuated (Wijkman \& Rockström, 2012). Almost half a century after global leaders first acknowledged the problem of unsustainable development (at the 1972 UN Conference on the Human Environment) not a single country can demonstrate that it has achieved absolute decoupling of economic growth and a comprehensive measure of environmental pressures and impacts (UNEP, 2011).

A growing catalogue of social and human health conditions can be linked to society's material overconsumption. The papers in this SV highlight climate change (HirschnitzGarbers, Tan, Gradmann, \& Srebotnjak, 2014; Kuramochi, 2015), waste and environmental pollution (Van Ewijk \& Stegemann, 2014), depletion of natural resources (Arvidsson, Kushnir, Molander, \& Sandén, 2015; Hirschnitz-Garbers et al., 2014; Schandl et al., 2015), biodiversity loss, and ecosystem degradation as the important ecological challenges facing global society. Exposure to pollutants in air, water, food, and soil has numerous adverse

\footnotetext{
${ }^{1}$ As well as being self-explanatory in the sustainability context, REDUCTIONS is an acronym for "Reducing Environmental Degradation \& Unsustainable Consumption Trends \& Impacts On Nature \& Society". The REDUCTIONS project was initiated by the Institute for Global Environmental Strategies of Japan which led a consortium including the Global Research Forum for Sustainable Production and Consumption, the World Resources Forum, and the Wuppertal Institute. The project identifies, describes and analyses opportunities for reducing material and energy throughput and emissions of production-consumption systems. It demonstrates reduction possibilities in different systems of provision and highlights effective characteristics and implementation mechanisms of reduction policies and practices.
} 
health effects, including cancer, lung disease, heart disease, brain damage, infertility, birth defects, and immune system impairment (WHO et al., 2015; World Health Organization, 2014). In Africa, one of the fastest growing economic regions with a number of promising niches for sustainable development, the overall exploitation of natural resources is damaging ecosystems and poisoning freshwater and agricultural lands, and leading to unemployment growth (Léautier \& Hanson, 2013) and armed conflicts (Escobar, 2006; Le Billon, 2001), while depriving the region of the natural resources that would support human development (Bardi, 2014). In developed and developing countries, rising inequality, economic and social distress and unrest, and increasing failure of government policy to provide welfare to citizens are rising.

This SV started with a simple question with wide-ranging implications: how can global society drastically reduce its material throughput and emissions to stay within ecosystem boundaries while securing wellbeing for all, and within a timeframe that avoids irreversible ecological harm? In assessing the need for absolute reductions, and seeking solutions, the research presented in this SV identifies four key issues that need to be addressed: (i) the cause of unsustainability, identifying the main drivers of material and energy use and emissions and how they are represented in different locations; (ii) the magnitude (intensity) of the problem, including the size of the expected impacts for environment and human health; (iii) the scope (spread) of the problem, including how far-reaching the consequences could be, and asking which groups and regions are affected most; and (iv) the urgency of the problem, identifying how soon it should be addressed to avoid large adverse impacts on society and environment.

The authors of this special volume and the sustainability science research community agree that the magnitude, scope and urgency of the sustainability challenge command nothing less than drastic change in global "civilisation", including a radical transformation of the institutional arrangements and socio-technical systems that facilitate the pursuit of wellbeing. One of the most critical challenges for global society is thus to bring the consumption of materials and energy, and the generation of waste and emissions, within ecological limits. This needs to be systematically accomplished quickly enough to avoid serious irreversible damage to the planet's life-supporting systems. Urgency is further accentuated when considering positive feedback loops within ecological systems (Friedlingstein et al., 2003; Heimann \& Reichstein, 2008; Scheffer et al., 2006; Schuur et al., 2015) that accelerate ecosystem decline. Further compounding the challenge, absolute reductions must be systematically accomplished against a backdrop of inequality and widespread poverty which necessitates that consumption levels of large segments of society need to be increased in order to meet their basic needs.

\section{Why absolute reductions: detangling system complexities}

Authors of several papers in this SV examined efficiency improvement approaches to resource use, presenting sobering conclusions about prospects of absolute reductions with current appetite for resources, and institutional arrangements. Hirschnitz-Garbers et al. (2014) observe that existing infrastructure in the European Union is mainly designed to use electricity generated from fossil fuels, and the long lock-in times for such infrastructure foster 
the use of fossil fuel energy carriers and hinder investments in alternative investments in renewable energy. Also in this SV, Van Ewijk \& Stegemann (2014) analyse the applicability of the waste management hierarchy - an order of waste treatment options (starting with waste prevention, reuse, recycling, recovery, and finally landfilling as a least desired option) that has heavily influenced OECD countries and is designed to reduce environmental impacts. They argue that waste prevention (a reduction approach) is fundamentally different from waste management, and waste managers are practically powerless when it comes to prevention. Thus in policy implementation, arrangements using the waste hierarchy can hamper waste reduction efforts by including prevention in a toolbox essentially meant for waste managers.

Current approaches to resource management lack a systems-wide perspective and fail to respond to the multi-dimensional nature of these complex problems. For many types of resources there is a long time-lag between overconsumption and serious negative effects (Hertwich, van der Voet, \& Tukker, 2010). The impacts of overexploitation tend to accumulate over time and to be non-linear in their impacts. Overfishing and agriculture that depletes soil carbon, for example, can go on for a considerable time until serious impacts emerge, but when this happens the impacts can be both rapid and severe. Furthermore, technological advances, such as more effective fishing trawls, can provide temporary relief when resource stocks dwindle, giving the illusory impression that resource constraints are non-existent or too far into the future to be relevant (Roberts, Hawkins, \& Gell, 2005; Cheung et al., 2010). A food and water crisis may put regions at risk that are considered essential suppliers for the world economy (Bleischwitz, Johnson, \& Dozler, 2014). As a result of such long time-lags human society does not receive timely feedback on the harmful consequences of its resource overuse. Actions to limit resource consumption therefore risk being delayed, possibly until serious irreversible damages have already occurred. System dynamics such as the above are reflected in the paper by Nunes et al. (2014) on modelling sustainability performance of systems.

One of the most obvious indicators of how human activities are changing the planetary system is human-induced climate change. The International Energy Agency (IEA) has warned that "energy efficiency can keep the door to $2^{\circ} \mathrm{C}$ open for just a bit longer". The policy goal of limiting global warming to $2^{\circ} \mathrm{C}$, let alone the aspirational $1.5^{\circ} \mathrm{C}$ goal of the COP21 Summit in Paris, "is becoming more difficult and costly with each year that passes" (IEA, 2012). The agency delivered a stark assessment, that four-fifths of the $\mathrm{CO}_{2}$ emissions allowable by 2035 are already locked-in by existing power plants, factories, buildings, etc. and that action to reduce $\mathrm{CO}_{2}$ emissions needs to be taken very soon to avoid all allowable $\mathrm{CO}_{2}$ emissions being locked-in. In addition, more recent climate modelling suggested that the $\mathrm{CO}_{2}$ that can be emitted while keeping global temperature below the $2^{\circ} \mathrm{C}$ increase may be considerably smaller than previously projected (Rogelj et al., 2016). If so, decommissioning existing energy-intensive infrastructure is an even more urgent task and the possibility of adding new energy-consuming techno-structure is very limited.

The other important aspect of achieving the climate policy outcomes is the decarbonisation of the global energy system. This can be achieved through many now cost-effective renewable 
energy options such as solar, wind and geothermal in combination with increasing carbon sequestration through forestation. While investments into renewable energy generation capacity are growing fast in many countries, most notably in China, the share of renewables in the total energy supply is still rather low in most countries.

Attempting to address resources or unsustainability issues one-by-one misrepresents the dangers by isolating single strands in a vastly complex socio-ecological system. Recent research results show that society is yet to fully understand the confluence of cascading and exacerbating issues stressing interlinkages across resource use patterns - the resource nexus (Bazilian et al., 2011; Giurco, McLellan, Franks, Nansai, \& Prior, n.d.; Adnan, 2013; Andrews-Speed et al., 2014). The resource nexus can be defined as the set of context-specific critical interlinkages between two or more natural resources used as inputs into socioeconomic systems. In this SV, the paper by Cazcarro et al. (2014) studied the interlinkages between economic policy, agricultural practices, and water stress in Spain. The authors documented that intensive agriculture and increased farm size have led to greater efficiencies and productivity, but involve potential risks to the environment. Especially in, but not limited to, livestock production and modernisation, in addition to global warming from methane and nitrous oxide, a significant risk of water pollution due to livestock intensification may come from nitrates, from percolation through the soil of inorganic nitrogen, and ammonia emissions linked to acidification and eutrophication.

An often highlighted nexus is that between food, water, and energy (Bazilian et al., 2011; United Nations Economic and Social Commission for Asia and the Pacific (UNESCAP), 2013), three key resource areas upon which human biological survival and social stability are totally interdependent. Globally, there is increasing incidence of droughts and floods, and shortage and pollution of water. Many urban areas are confronted with water stress, characterised by scarcity or pollution of drinking water and that for other domestic uses. Agriculture is heavily dependent on water, consuming about $70 \%$ of global freshwater demand. Food production and water demand are projected to increase, owing to growing world population and changes in diets towards increasing meat consumption. Energy to power the world economy competes with agriculture for water, which is needed in extraction, transport, and processing of oil, gas and coal. The IEA estimated that water withdrawals for energy in 2010 were 583 cubic billion metres, of which the annual volume of water withdrawn but not returned to its source was about 66 billion cubic metres. It then projected that water consumption to meet energy demands will increase by $85 \%$ between 2010 and 2035, reflecting a move towards more water-intensive power generation (IEA, 2012). Unless there is a drastic change, this increase in energy demand will primarily be met by burning fossil fuels, which is now well established as a primary cause of climate change.

Renewable energy options are now available in many countries and they are increasingly becoming competitive in price compared to fossil fuel-based energy generation despite very large government subsidies into the fossil energy regime in many countries. Some countries, and also city governments, are spearheading investment into renewable energy. Germany now produces close to $15 \%$ of its energy needs from renewables (Hake, 2015). Nevertheless, moving to renewable energy requires a change in regime which is often contradicted by 
vested interests of businesses and shareholders that profit from the current energy provisioning regime.

The resource nexus debate also has a security dimension (Lee et al., 2012). Failures to manage shared resources such as transboundary water, energy sources and food resources, create tensions that can easily lead to conflicts. The World Resources Forum has warned that in addition to increasing population, increasing need for food, water and energy, economic disparity also often exacerbates this nexus of risks as governments and consumers seek shortterm, unsustainable solutions to economic hardships such as growing high-value, waterintensive export crops in water-deprived regions (WEF, 2011). The Forum and other analysts expect an acceleration of global risks such as protectionist measures, resource nationalism, and geopolitical tensions. There is ample evidence of conflicts among geographic regions owing largely to resource scarcity (Escobar, 2006).

\section{Systemic challenges to absolute reductions}

Growing scientific knowledge of how economic activity drives resource consumption, ecological degradation, climate change, and human health impacts, as well as on associated social challenges, has failed to inspire decisive and effective action. The reasons behind these gaps between knowledge and action are multiple and complex. From papers in this SV, we identified four main challenges to bridging these gaps: the resource-intensive conventional template of development, macroeconomic structures and trade policies creating burdenshifting and inequality, a resource-efficiency improvements fallacy, and the dominant consumerist culture and lifestyles. While these four challenges are not exhaustive they reflect messages from papers in this SV and illustrate the systemic nature of the issues associated with society's resource consumption.

\subsection{A resource-intensive template for development}

The conventional development model, based on urbanisation and industrialisation, is very resource intensive. A paper in this SV by Kalmykova et al. (2014) analysed the urban metabolism of two cities in Sweden; and another paper by Seebauer et al. (2014) compares carbon footprints of shopping in urban and rural settings. Together their findings indicate that as more people adopt urban lifestyles and consumption patterns, annual per-capita resource consumption soars. Along similar lines, Laakso \& Lettenmeier (2014), Mair et al. (2014) and Hirschnitz-Garbers et al. (2014) show that that as countries develop and grow affluent their per-capita demand for resources increase to unsustainable levels, exceeding a fair earth-share (the level that could sustainably be enjoyed by all humans). All high-income countries have high levels of per-capita resource consumption, especially when the material consumption embedded in imports is taken into account (see Mair et al., 2014). In the absence of a role model showing how a country could be developed on a sustainable basis, countries climbing the development ladder face a dilemma: to remain poor with a low impact on the planet, or to modernise and have their dependence on natural resources soar (Akenji \& Bengtsson, 2014).

Industrialised countries, whose citizens have enjoyed high material standards for a long time, are now locked-in through their entrenched resource-intensive systems. The paper by Brown \& Vergragt (2014) used the United States as an example showing that infrastructure, 
institutions, and social norms, as well as individuals' habits and preferences, have evolved in conjunction with increasing resource use. To significantly scale down their resource consumption from the current high levels would be very difficult and take considerable time even with strong efforts. Brown \& Vergragt suggest that an initial challenge would be to build broad-based support for this kind of transformation and to gain citizens' acceptance of the kind of government policies needed.

Discussions on resource demand should not, however, ignore that there is already a large consumer class in the global south, especially in middle-income countries. This rapidly growing demographic is enjoying material standards comparable to those common in OECD member countries. In addition, disparity in income and consumption is growing in many industrialised countries, where increasing numbers of people can only afford lifestyles that demand few resources. Inequality in resource access and consumption thus exists both within countries and among countries.

\subsection{Macroeconomic structures and trade}

Prices of goods and services do not properly reflect resource depletion and associated detrimental impacts; this is due to the ways markets operate as well as to governmental policies. In this SV, Hirschnitz-Garbers et al. (2014) cited the example of the low price of phosphorous in the international market; because it does not reflect the looming scarcity and related pollution, phosphorous recycling is not widely undertaken and market prices for recovered phosphorous are not competitive. This is an example that governments do not usually require extractive industries and consumers of natural resources to pay the full price of negative externalities in the form of environmental damage and livelihood impacts. In fact, they tend to provide direct subsidies to protect jobs in extractive sectors, to support export industries and to reduce consumer prices. Such subsidies provide multiple stimuli for excessive, unsustainable, resource consumption. Current market prices only reflect costs of resource extraction and the short-term balance of supply and demand; future effects tend to have much less influence or are totally externalised to the ecosystems and to the global society as a whole. In addition, market prices do not properly reflect delayed and non-linear effects of resource consumption, resulting in under-pricing. In fishing, for example, increasingly intensive exploitation of a fishery may in the short-term only result in small increases in consumer prices, not reflecting the gradually increasing risks of sudden ecosystem collapse.

The impacts of excessive resource extraction are often felt in locations far from where critical decisions on investment and purchasing are made. In this SV, Cazcarro et al. (2014) use an innovative approach combining multi-regional input-output (MRIO) models and GIS tools to study how macroeconomic policies can have local effects. Their study analysed the grey water footprint (the volume of freshwater that is required to assimilate the load of pollutants based on existing ambient water quality standards) imposed through economic activities on water resources in a region. It provides an example of how trade activities and meat production responding to nationally adopted policies could have strong ramifications at local level - sometimes far away from the beneficiaries of those policies or trade activities. 
Two other papers in this SV provide examples of distancing. The paper by Schandl et al. (2015) analyses resource flow patterns and argues that supply chains have become increasingly global and complex, resulting in trade in primary resources being the fastest growing component of global resource use and along with it a separation of consumption and production and the resultant eco-burden shifting. Critically, wealthy OECD countries have outsourced a large part of their material intensive production to developing countries with the economic benefits occurring in OECD countries and the environmental and social burdens occurring in resource supplying countries.

To substantiate the effect of distancing, Mair et al. (2014) introduced a sub-system framing, by adapting a global multi-regional input-output model (GMRIO) to allow them to make robust estimates of sectoral, production footprints. The model was used to assess sustainability aspects of the Western European textile and clothing industry between 1995 and 2009; they found evidence of substantial inequities and negative environmental impacts embodied in macroeconomic structures. In the period under study, most of the labour for producing textiles and clothing consumed in Europe was supplied by BRIC countries notably China and India - with well-documented evidence of poor working conditions, restricted rights for workers and high frequencies of fatal accidents. The authors also found substantial inequities between wages in Western Europe and BRIC by matching findings with those of other studies which showed that highly skilled jobs were retained in Europe while low skilled jobs and low value portions of production chains were relocated to developing countries. Also supporting the growing acknowledgement by research that offshore carbon emissions constitute increasingly bigger portions of the carbon footprints of developed countries, the authors found that a large portion of the growth in BRIC contributions to the carbon footprint of production after 2002 was a displacement of carbon emissions, primarily from Europe. The burden-shifting in itself was problematic, but further compounding this was the finding that the carbon intensity of the countries to which production was shifted was much higher - the carbon intensity of BRIC production between 2002 and 2007 was greater than the carbon intensity of Western European production in 1995. The key conclusion is that not only is unsustainable trade fostering social injustice, it is leading to overall increases in carbon emissions. This has been repeatedly documented in many research findings: the footprints of developing countries are largely defined by the appetites of developed countries - those who are most in need of development actually produce much, in a material sense, not for themselves but rather for those who already have.

\subsection{The enhanced efficiency fallacy}

Policy efforts to address natural resource consumption have focused on enhancing efficiency rather than on limiting absolute amounts used. Improved efficiency, the ability to meet demand with lower inputs of natural resources (or to meet increasing demand with a constant amount of resource input), is an important element for achieving sustainable resource consumption, but is not sufficient. Innovation is key to overcoming environmental constraints, but needs to be conceptualised in its systemic dimensions which has important implications for policy too (Bleischwitz, 2012). A paper by Arvidsson et al. (2015) in this SV discusses this fallacy: that growing consumption tends to outpace efficiency improvements, 
and that rebound effects (where efficiency improvements themselves stimulate increasing consumption) have offset or limited the resource-saving potential of efficiency gains (see Hertwich, 2005; Kojima \& Aoki-Suzuki, 2015). This is in agreement with standard economic theory that efficiency gains stimulate higher economic growth which in turn is associated with higher levels of resource use and emissions.

Decoupling, a concept closely related to efficiency, has attracted significant policy attention. It refers to the idea that economic activity can become less resource intensive so that resource consumption either grows at a lower rate than the economy (relative decoupling) or that resource consumption decreases while the economy grows (absolute decoupling). Decoupling is an important narrative and hypothesis, and is a very useful policy notion in principle. There is a problem, however, with how it has been framed in policy discussions where the key question has been how decoupling can be achieved rather than whether it can be achieved to the extent needed, and within the timeframe needed, to prevent ecological overshoot. The notion of "relative decoupling" can easily cause confusion, especially among non-experts, since it can give the incorrect impression that society is on track towards sustainability although in reality natural resource consumption continues to grow. In fact, even the term "absolute decoupling" can be misleading since it does not consider whether natural resource consumption is decreasing fast enough. The way the notion of decoupling is commonly used in policy discourse gives priority to growing economic activity with ecological sustainability only a secondary concern. Schandl et al. (2015) modelled the potential for carbon pricing and investment in resource efficiency to decouple economic growth from energy use, material use and carbon emissions. Their results show that globally, aggressive carbon abatement and resource efficiency can work together to achieve relative decoupling for material use and carbon emissions at small cost to the economy. Energy use will continue to rise and emissions will decrease mainly through decarbonisation of the energy system. The ambitious policy settings will, however, not allow for absolute reductions in energy or material footprints, though carbon footprints could be reduced in absolute terms.

The ambition to make society more resource efficient has spurred strong interest in recycling materials. Recycling holds significant potential for reducing energy consumption and limiting the need for resource extraction. It has, nevertheless, limits as an approach to achieve sustainable natural resource use. The environmental benefits of materials recycling are well documented in the literature, but the limitations have been less well studied and are not so widely acknowledged. As shown below, a number of papers in this SV discuss challenges associated with recycling and provide arguments for why it cannot be relied upon as the only approach to solving waste problems or achieving absolute reductions in material throughput and energy use:

i. Recycling can save resources, but it also requires input of resources, which can partly offset the gains. The whole recycling chain, including collection, transportation and material processing consumes energy (often fossil fuels) and generates pollution. In this SV, Kuramochi (2015) illustrates this point by showing that resource inputs needed for scrap steel recycling can be very high; 
ii. For many materials, recycling can only be carried out in a limited number of cycles without additional input of virgin resources; each processing degrades the quality of the material, which determines the feasibility of close-loop recycling. To assess the limits of repeated recycling, in this SV Chen et al. (2014) introduced a metric called cumulative lifetimes to estimate the number of times a material input can be used in the economy. Their analysis shows that for paper recycling in Taiwan, one unit of virgin input can provide 1.786 lifetimes, based on the production efficiency and recycling performance in 2010 ;

iii. The quality of recycled materials is in many cases inferior to that of virgin materials, either as a result of physical or chemical degradation of the material itself or due to contamination. This means that recycled materials can only be used for certain applications with low technical, hygienic and aesthetic demands. Kuramochi's (2015) techno-economic assessment of the iron and steel industry in Japan highlights the above problems; similarly, Chen et al. (2014) demonstrated this with the case of recycled paper in Taiwan;

iv. In practice, only a fraction of total waste can be collected and recycled. This is demonstrated by the very low return rate of used mobile phones for recycling, as shown in this SV by Welfens et al. (2015) who quote a study by Nokia showing that less than $10 \%$ of all mobile phone users worldwide returned old phone handsets. Also, materials with low market value, such as packaging and paper, are hard to collect effectively and therefore end up in dumps or landfills, or burnt in the open or in incinerators;

v. For some materials and applications there can also be dissipative losses when materials are released to the environment during use and therefore become unavailable for recycling. The corrosion of metals and leakage of phosphorus from agriculture illustrate this limitation;

vi. Certain types of waste, including everyday waste such as composite packaging, are technically challenging to recycle. As products get increasingly complex, containing different types of material, it becomes more difficult to separate the materials from each other, and then to recycle each of them. One of the most commonly used materials in modern society - concrete - cannot currently be recycled. Pettersen (2014) argues in this SV that design for sustainability could address several of the issues of difficulty of separation, and even encourage reuse or remanufacturing; and

vii. The amount of materials-in-use (material stock) continues to increase, also in highly industrialised countries. The resource demand associated with growing material stocks cannot be met through recycling, even if recycling rates would reach $100 \%$; it requires input of virgin resources.

These examples do not refute the importance of recycling and, in fact, the huge potential for reduced use of virgin resources. Kuramochi (2015), for example, shows the huge saving potential in Japan of choosing the most effective approach to recycling scrap steel. The 
emphasis is on recognising limitations, and not relying on recycling as the only efficiency improvement approach towards absolute reductions.

\subsection{Entrenched consumerist lifestyles}

Achieving absolute reductions would require changes in lifestyles (Hirschnitz-Garbers et al., 2014; Kalmykova et al., 2014; Seebauer et al., 2014), especially in industrialised countries and among the growing consumer class in emerging economies. Laakso \& Lettenmeier (2014) estimated in this SV that an $80 \%$ reduction in material consumption is required for citizens in industrialised countries - from over 40 tons/person/year down to a sustainable target of 8 tons. In section four we address the complexity of setting targets for material consumption and emphasise that this target should not be seen as a precise sustainable level but should be regarded as indicative of the magnitude of change that would be desirable. Translating the reductions targets into effects on everyday activities offers opportunities to appreciate the needed shift in lifestyles. Table 1 provides an illustration, using the case of Finland to represent an over-consuming country.

Table 1: The current material footprints for Finland and proposed targets for absolute reductions by 2050 in key domains

\begin{tabular}{|c|c|c|c|c|c|c|}
\hline \multirow[t]{2}{*}{$\begin{array}{l}\text { Consumption } \\
\text { domain }\end{array}$} & \multicolumn{2}{|c|}{$\begin{array}{l}\text { Current material } \\
\text { footprint } \\
\text { (based on 2005-2007 } \\
\text { data) }\end{array}$} & \multicolumn{2}{|c|}{$\begin{array}{l}\text { Sustainable material } \\
\text { footprint }\end{array}$} & \multicolumn{2}{|c|}{$\begin{array}{l}\text { Required } \\
\text { reduction }\end{array}$} \\
\hline & ton/person/year & Share & ton/person/year & Share & Factor & Share \\
\hline Nutrition & 5.9 & $15 \%$ & 3.0 & $38 \%$ & 2.0 & $49 \%$ \\
\hline Housing & 10.8 & $27 \%$ & 1.6 & $20 \%$ & 6.8 & $5 \%$ \\
\hline $\begin{array}{l}\text { Household } \\
\text { goods }\end{array}$ & 3.0 & $7 \%$ & 0.5 & $6 \%$ & 6.0 & $83 \%$ \\
\hline Mobility & 17.3 & $43 \%$ & 2.0 & $25 \%$ & 8.7 & $88 \%$ \\
\hline Leisure & 2.0 & $5 \%$ & 0.5 & $6 \%$ & 4.0 & $75 \%$ \\
\hline others & 1.4 & $3 \%$ & 0.4 & $5 \%$ & 3.5 & $71 \%$ \\
\hline Total & 40.4 & $100 \%$ & 8.0 & $100 \%$ & 5.1 & $80 \%$ \\
\hline
\end{tabular}

Source: Lettenmeier, Liedtke, \& Rohn (2014) 
There are many reasons why changing lifestyles towards sustainability remains difficult. Government policies addressing lifestyles have so far primarily focused on consumer awareness-raising and encouraging the purchase of green products. This focus on persuading individual consumers to change puts the onus on the most visible stakeholder group instead of upon producers and retailers who arguably have more influence over product design and marketing.

The environmental impacts of lifestyles are not intentional but rather are a consequence of people aspiring to fulfil their needs and desires, and functioning in society. Knowledge or awareness of sustainability aspects of consumption and lifestyles options does not usually lead to intended actions. This knowledge-action or intention-behaviour gap suggests that: awareness is easily subordinated by lack of access or lock-in to modes of available options; people are driven by ideologies (such as the belief in freedom of choice in democratic societies); and the power of advertising by corporations far overwhelms the limited effect of consumer awareness. Papers in this SV (Brown \& Vergragt, 2014; Fuchs et al., 2014; Mohd Suki, 2015) argue that shifting to sustainable lifestyles requires changes in the societal value system (including the socially shared ideas on what contributes to wellbeing and what indicates social status), and reviewing the choice architecture and infrastructure enabling and constraining lifestyles.

Lifestyles occur within, and are both enabled and constrained by broader social and physical contexts. Existing infrastructure and prevailing services in wealthy parts of the world predetermine basic levels of resource use that currently exceed sustainability limits (see, in this SV, Knoeri, Steinberger, \& Roelich, 2014). Laakso \& Lettenmeier (2014) in this SV introduced a household-level sustainability transition methodology to understand possibilities for sustainable resource use by households in Finland and how this might be reconciled with their visions of sustainable lifestyles. Of the 45 households examined, 44 exceeded the eightton footprint limit, by factors of up to 15 . Although the households with the smallest footprints were minimum-income households, most still exceeded the level of sustainable material use. In approaching lifestyles, it is important to differentiate between factors that can be realistically addressed individually or by the household, and those that are, in practice, beyond individual control. Breaking society's lock-ins to unsustainable lifestyles requires not only changes in consumer attitudes, but also alterations in overall design and configuration of infrastructure and facilitating systems (Akenji, 2014).

The paper in this SV by Knoeri et al. (2014) showed that infrastructure is a crucial intermediary between socioeconomic activities and consumption of environmental resources. Studying design of end-user infrastructure for systems such as energy, water, and waste, they provide examples to demonstrate that the way utility product delivery to the end-user is currently assessed and measured has three basic shortcomings: (i) billing metered quantities instead of services prevents efficiency solutions; (ii) flat rate charges disincentivise efficiency and sufficiency behaviour; and (iii) highly standardised "one size fits all" solutions lead to technological lock-in ignoring the variety of services required by end-users. One of the contentions by the authors was that privatised utility companies, whose profit model depends 
on volume sales, do not prioritise needed reductions. Such business models may, therefore, be inherently unsustainable, and currently contribute to blocking sustainability transitioning.

The four challenges introduced in this section show that the main systemic challenges to absolute reductions include: the resource-intensive conventional template for development, macroeconomic structures and trade policies creating burden-shifting and inequality, a resource-efficiency improvements fallacy, and the dominant consumerist culture and lifestyles. Addressing these challenges and moving towards absolute reductions would need targets to guide the sustainability transition. Section four discusses possible material targets.

\section{What to reduce, how much and by when: complexity in determining reduction targets}

Although the need for reductions has been established, there is still no clarity on the magnitude of such reductions or on the timeframe. The authors of the papers included in this section address how such targets could be established. For climate change, there are agreed time-bound targets, but for other resources and stressors there are no corresponding targets. In order to set reduction targets, scientific knowledge about ecological limits is required, but defining acceptable levels of risk has also a political and ethical dimension. For resources such as fossil fuels, land, water and fish stocks, there is some understanding of the limits and when long-term depletion and degradation occurs. For other energy and material resources, the limitation of the resource base is less clear. Instead, knowledge of the assimilative capacities of nature could be used for target setting (BIO Intelligence Service, 2012).

Absolute reductions in material use are connected to the logic of planetary boundaries, a concept coined by Rockström et al. (2009). According to these authors, the planetary boundaries define "the safe operating space for humanity with respect to the Earth system". If these boundaries are surpassed, important Earth subsystems risk shifting to a new state, with potentially disastrous consequences for the ecosystems upon which humans are totally dependent. Using the DPSIR framework one can observe that the planetary boundaries are mainly defined at the level of State, while absolute reductions in contrast addresses the Pressure level. The concept of absolute reductions is, therefore, complementary to the planetary boundaries and tries to get one step closer to identifying what changes in society are needed to achieve ecological sustainability at the global level.

Translating the proposed planetary boundaries into boundaries for resource use is, however, not a straightforward exercise, perhaps with the exception of freshwater. We therefore find it more practical to start with the main resource categories, and then to define potential limits for each category. Researchers have begun to define broad resource categories and related human "footprints": the water, land and material footprints (e.g. Tukker et al., 2014). In addition, the carbon footprint is an important indicator of human pressure on the environment. These four categories form a starting point for suggesting indicative planetary limits to resource consumption. 
The UNEP Emissions Gap report found that in order to stay within a $2^{\circ} \mathrm{C}$ temperature rise, greenhouse gas emissions need to be brought to zero at some time between 2080 and 2100 . As an intermediate goal, these emissions should be in the $18-25 \mathrm{Gt} \mathrm{CO}_{2}$-eq range by 2050 (UNEP, 2014; see also IPCC et al., 2013; Meinshausen et al., 2009). With a global population of between 9 and 10 billion (Gerland et al., 2014), this corresponds to around 2-2.5 ton/capita/year. However, the recent COP21 agreement in Paris suggested a more stringent target of a $1.5^{\circ} \mathrm{C}$ temperature increase, which would imply a significantly lower per-capita target.

The Water Resources Group (WRG, 2009) claimed that by 2030 the demand for freshwater is likely to exceed sustainable supply by $40 \%$. With the current availability of blue water being some $250 \mathrm{~m}^{3} /$ capita/year (Tukker et al., 2014) this suggests a limit of water use of around $150 \mathrm{~m}^{3}$ per capita/year by 2030 . Hoekstra \& Wiedmann (2014) mention a maximum global blue water footprint of 1100-4500 billion $\mathrm{m}^{3} /$ year, which with an expected 10 billion people on Earth by 2050 implies a limit of 110-450 $\mathrm{m}^{3} /$ capita. Rockström et al. (2009) proposed a boundary of 4,000 billion $\mathrm{m}^{3} /$ year, or $400 \mathrm{~m}^{3} /$ capita assuming a 10 billion world population. One can conclude that for water usage there is a range of suggestions for planetary boundaries. Additionally, one has to acknowledge that the sustainability of water extraction is highly location dependent, so global targets may have limited relevance, while targets at the level of watersheds may be more useful (e.g. Pfister \& Hellweg, 2009; Ridoutt \& Huang, 2012).

Currently around 88 million $\mathrm{km}^{2}$ of land is used by humans for agriculture, forestry, and infrastructure. Most authors agree that the potential for expanding land use for human purposes is very limited: "halting biodiversity loss requires agricultural land [cropland + permanent pastures], at least, to be stabilised by 2020" (van Vuuren \& Faber, 2009). UNEP (2014) suggested a maximum possible expansion of cropland of about 1.5 million $\mathrm{km}^{2}$. Dividing the $88-89.5$ million $\mathrm{km}^{2}$ by the future population in 2050 of 9 to 10 billion people provides a land availability of $0.009-0.01 \mathrm{~km}^{2}$ per person. However, a target derived in this way in essence accepts that current pressures on biodiversity by human land use are acceptable, in contrast to results of studies showing that a reduction of such pressures is necessary (Millennium Ecosystem Assessment, 2005). Additionally, as is the case for water, one has to acknowledge that simply counting square metres is too simplistic. The quality, ecological value, or productivity of land should ideally be taken into account. Climate change adds further to this complexity since it affects the productive potential of land.

Determining a target for materials (often divided into categories such as energy materials, biotic materials, metallic minerals and other minerals) proves to be even more complicated. Dittrich et al. (2012) proposed an initial target of 8 tons per capita/year (later also applied by Hoekstra \& Wiedmann, 2014). More recently, Bringezu (2015) proposed targets between $2 \mathrm{t} /$ person and $10 \mathrm{t} /$ person differentiated between different indicators for biotic and abiotic resource consumption. However, these suggested targets derived their values from the assumption that material use should be reduced in comparison to the global consumption level of 2000 - considering this a sustainable level without further assessment. Hence, unlike the approach taken by Rockström et al. (2009), and Steffen et al. (2015), the boundaries 
suggested for materials use were not based on a cause-effect analysis of the level at which material use could surpass planetary boundaries or tipping points.

Since the materials categories have such diverse characteristics, we argue that the discussion on boundaries with regard to material use should be held by category. For energy materials, any target would be strongly related to the carbon footprint target discussed earlier. For biotic materials (i.e. agricultural and forestry products), any target would be related to limits with regard to land use and water use - for instance, higher food production for a larger and wealthier global population would have to be offset by an equivalent rise in land productivity and water productivity. For non-metallic minerals, the situation can be highly diverse - key building and construction materials like sand are neither scarce nor particularly harmful. Thus, it is counterintuitive to propose radical reduction targets for construction minerals. In contrast, mineral fertilisers such as phosphorus cannot be substituted, may become scarce in the future, and are critical from a planetary boundary perspective. However their use is required for feeding the world's population in the future. For metallic minerals, again the situation is highly differentiated. Some metals require high energy inputs (hence resulting in high $\mathrm{CO}_{2}$ emissions) in the refining step, which may limit their use. Reserves of metals are, however, not an indicator of absolute availability - mining firms do surveys until they know where to mine the metals needed in the next 20 to 30 years; only when reserves are below this time horizon is money spent on new surveys. Ore grade development could become a key indicator for assessing the intensity of using energy and water for extraction, and for generating mining waste. Current so-called "criticality" studies focus on a few materials and particularly their political availability, influenced by for example how many countries can provide the metal in sufficient quantities to meet expected demand. The possibility of effectively collecting and recycling individual metals also needs to be considered when discussing reduction targets. Metals that have high dissipative flows and where applications are highly dispersed have low potential for recycling and may require stricter targets.

Unlike the carbon, water and land footprint targets discussed in the previous paragraphs, material footprint targets are not based on an assessment of physical limits or irreversible losses of critical parts of natural capital. The material footprint indicator combines material categories for which future reduction targets should differ. While this indicator can be useful as a highly aggregated measure of planetary pressure, we thus refrain from proposing a single, indicative target value for annual, per-capita material use.

While authors of this paper underscore the complexity of setting targets for consumption we argue that trying to do so is useful. Even when sustainable use limits cannot be precisely defined, it is important to try to reach agreement on the desired direction as well as the urgency and timeframe - whether the consumption of a certain resource can be allowed to grow further, should be stabilised, or whether a reduction is called for. In the final section of this paper we therefore include indicators and targets for absolute reductions as a priority area for further research. 


\section{Facing a resource constrained future: towards a research and action agenda on absolute reductions}

The papers included in the SV, while being far from exhaustive, illustrate a range of research approaches that can help society respond to this "knowledge need" (see Table 2). The essay by Fuchs et al. (2014), highlights the need to question the power relations established in current production-consumption systems. An understanding of power dynamics offers a better understanding of resistance to change and facilitators of a transition. Every change in policy will ultimately change the pattern of who gains and who loses compared with the status quo; existing power relations also influence who is going to support or undermine policy initiatives designed to achieve an equitable and environmentally sustainable socioeconomic system. There is ample potential for material substitution (Allwood and Cullen 2010), industrial symbiosis (Chertow 2007) and remanufacturing (Savaskan, Bhattacharya and Van Wassenhove 2004) that would support delivering housing, mobility and consumer goods at much lower environmental cost. In this SV, Vìgants et al. (2015) examine the process of eco-innovation diffusion of environmentally friendly substitutes and conclude that one of the biggest barriers in consumer products is social acceptance.

Arvidsson et al. (2015) in this SV also assess the potential for graphene to be used as a substitute for indium tin oxide as a material in transparent electrodes used for computers and mobile phones and other electronic applications with transparent screens. Their conclusion points to the risk that introducing more efficient substitutes without addressing increasing material consumption could introduce "higher order effects" such as rebounds.

A policy mix that would achieve reduced material throughput would certainly include global pricing systems for carbon to set the global economy on a path to stay within $1.5^{\circ} \mathrm{C}$ of warming, as shown in this SV by Schandl et al. (2015). Current systems of production and incentives are geared towards increasing labour productivity often at the cost of declining resource productivity and declining wellbeing of society. An ecological budget and tax reform could be designed and enforced to raise a tax on primary resources. This could be achieved in revenue-neutral ways by reducing taxes on labour and business taxes. The resource tax would be increased over time in step with past productivity gains. Changing the cost of primary resources will provide incentives for industry clusters, industrial symbiosis and systematic progress toward sustainable, circular economies. A rapid transition from conventional energy generation to renewable energy would require decommissioning energy generation plants which would otherwise still be operable for many decades. It would also mean leaving fossil fuel reserves untouched and curbing investments in coal, oil and natural gas. In the face of the Paris Climate Conference it is essential to rapidly redirect investment to renewable energy, also because the risk profile of investment in conventional fuels has changed.

Table 2: Approaches to materials reductions from papers included in this SV

\begin{tabular}{|l|l|}
\hline & Related paper \\
\hline Substitution & $-\begin{array}{l}\text { Graphene as a substitute for indium tin dioxide in transparent } \\
\text { electrodes (Arvidsson et al., 2015) }\end{array}$ \\
\hline
\end{tabular}




\begin{tabular}{|c|c|}
\hline & $\begin{array}{l}\text { - Use of bio-based composites for construction materials (Miller, } \\
\text { Billington, \& Lepech, 2015) }\end{array}$ \\
\hline Carbon Taxation & $\begin{array}{l}\text { - Progressive global carbon pricing from 50 USD in } 2010 \text { to } 236 \\
\text { USD in } 2050 \text { to reduce emissions and materials use (Schandl et } \\
\text { al., 2015) }\end{array}$ \\
\hline Recycling & $\begin{array}{l}\text { - A techno-economic assessment of comparative recycling } \\
\text { methods of iron and steel (Kuramochi, 2015) } \\
\text { - Post-use collection of mobile phones for recycling (Welfens et } \\
\text { al., 2015) } \\
\text { - } \quad \text { Limitations of repeated recycling of paper (Chen et al., 2014) }\end{array}$ \\
\hline Sustainable lifestyles & $\begin{array}{l}\text { - Collaborative consumption - crowdsourced delivery of library } \\
\text { books (Paloheimo, Lettenmeier, \& Waris, 2014) } \\
\text { - Choice of retail channels and related carbon emissions } \\
\text { (Seebauer et al., 2014), and green purchasing (Maniatis, 2015; } \\
\text { Mohd Suki, 2015) } \\
\text { - } \quad \text { Household dematerialisation (Laakso \& Lettenmeier, 2014) }\end{array}$ \\
\hline $\begin{array}{l}\text { Design for } \\
\text { sustainability }\end{array}$ & $\begin{array}{l}\text { Design of provision systems and infrastructure for utility } \\
\text { services (water, electricity, etc.) for reduced end-use } \\
\text { consumption (Knoeri et al., 2014) } \\
\text { - } \quad \begin{array}{l}\text { Design of television entertainment practices for reduced } \\
\text { material consumption (Pettersen, 2014) }\end{array} \\
\text { - Design of catering services to reduce food waste in the } \\
\text { hospitality industry (Pirani \& Arafat, 2015) }\end{array}$ \\
\hline Eco-innovation & $\begin{array}{l}\text { - Technology diffusion and use of micro-fibre cloth for surface } \\
\text { cleaning (Vīgants et al., 2015) }\end{array}$ \\
\hline $\begin{array}{l}\text { Managing power } \\
\text { dynamics }\end{array}$ & $\begin{array}{l}\text { - "Theories of social change" to address role of power among } \\
\text { stakeholders in perpetuating consumerism; illustration of power } \\
\text { dynamics to increase meat consumption (Fuchs et al., 2014) }\end{array}$ \\
\hline
\end{tabular}

The scientific community continues to add to our understanding of the resource challenges, further strengthening the rationale for considering limits to material growth and encouraging society to consider the need for absolute reductions in material throughput. While there is a large body of existing scientific knowledge that has not yet translated into government policies and practical action, we still see a need to extend our collective knowledge base especially on how society could transform towards sustainability. With this SV we hope to inspire more research, from various disciplines, on the topic of absolute reductions. We see a need especially for research on how society could operate, and achieve its objectives of poverty eradication, reduced inequality and enhanced human wellbeing, under tightening resource constraints and even under scenarios with shrinking input of natural resources. The recently adopted sustainable development goals (SDGs) highlight these potential tensions, since a number of these goals, such as zero hunger, clean water and sanitation, and access to clean energy, will require increased use of resources.

In this section we propose six domains of change that will require future academic research to provide the science that will inform policy and business decisions and guide the engagement of practitioners to work towards a sustainability transition. In these areas new knowledge is 
required and it needs to rely on high quality policy research and effective processes of joint learning among researchers, policy makers and practitioners. If the challenges identified are addressed there is significant potential for global society to embark on a global sustainability transformation.

A. From niche to norm. Many promising examples, demonstration projects and niches for sustainable consumption and production (as evident through this SV) exist but more research and policy initiatives are needed for extending the niches to become the general norm and underpin substantial transformation of the global economy. This reflects the truly transdisciplinary effort for transformative research and international collaboration as organised by the "Future Earth" initiative of the UN. Research needs to bridge the divide among social and natural sciences and would include conceptual innovation, new methods, datasets and indicators, modelling and engagement with policy and community. The role of the business community and the need for new business models is especially crucial to establish socioeconomic underpinnings for cultural change towards sustainability. While the four challenges identified in the special volume (see above) show the extent of the effort there are also signs of change including growing investment in renewable energy, sustainable buildings, electric mobility, remanufacturing and recycling. Well-designed policies would support those initiatives and enable a transition so that many local niches would become a global norm. Research thus should tackle the questions of how policy mixes and incentives at national and international scale can guide innovation and transformation. How do we build infrastructure that relies less on ever-increasing amounts of natural resources to provision energy, water, food, mobility and housing to a higher standard, to more people and at much lower environmental cost? How do fiscal systems need to change to encourage resource efficiency and reduction of natural resource use and emissions and to create incentives for systemic eco-innovations? What are the new models of collaboration and the new standards that will enable mass markets of consumer products to be redesigned for longevity and sustainability? Research addressing these policy questions must be comparative, inter- and transdisciplinary and would ideally be conducted in international collaboration involving researchers from emerging and developing countries.

B. Targets for absolute reductions. Objectives and targets are important for achieving desired sustainability outcomes. They must include reductions for regions that rely on high environmental pressures and impacts to make room for developing countries to grow their resource consumption. A global strategy of reduction and convergence on a sustainable level of per-capita material and energy use, and emissions, addressing the new sustainable development goals (SDGs) (UN Secretary General, 2014) and complying with global limits would require complex policy mechanisms and a level of global collaboration yet to be achieved. Science needs to identify which approaches and methodologies would allow policy to define targets and time-frames for natural resource consumption. For which natural resource categories and at what scale global, national, per-capita - should targets apply? How will policy address trade-offs (such as needing more natural resources to deliver the SDGs)? How will equity be ensured? How should such targets best be embedded in a policy mix and represented by institutional settings in order to be actionable by businesses and households? 
Targets must expand our insights from socioeconomic environmental science to establish core indicators, define suitable base years and corridors, and include equity goals. There is a need for research that (a) addresses different scales of global and regional targets and (b) carefully choses indicators that reflect production and consumption structures (i.e. disaggregating materials into useful subcategories) to allow for monitoring of policy success.

To address uncertainty, a research agenda for reductions will have to address the transformative function of targets and monitoring as a process of gaining orientation and continuously improving performance on physical indicators. Such an approach is in line with earlier recommendations of Gunnar Myrdal about means and ends, and with the more recent strands of transition management and co-evolutionary thinking, according to which actors experiment towards broader visions rather than follow determined trajectories towards fixed targets.

C. Managing linkages and substitutions ("the resource nexus"). Recent research has demonstrated the issue of deep linkages between natural resource use systems and in institutions that guide them. Research for reductions will need to address these linkages and trade-offs. How can problem-shifting associated with resource substitution be anticipated, assessed from a sustainability perspective, and managed? While the nexus research on such interlinkages between water, energy and food and other natural resources is an important starting point for identifying the most critical interlinkages, how can on-ground action allow barriers to be overcome at a regional or global level? This is important as better managing linkages would avoid sectoral approaches that exist in the policy community and dominate regional planning and turn them into opportunities towards achieving the SDGs. Fragile and vulnerable regions need be identified and deserve special research and policy focus. In addition, research needs to improve and develop modelling tools that can link environmental changes with the quest for jobs and prosperity to assess the dynamic and non-linear repercussions of environmental changes for social and economic outcomes. Research management will increasingly rely on mechanisms to extend research collaboration from regional to global and would benefit from a public global forum for natural resource reductions to arrive at better foresights and scenarios for the future.

D. Global resource governance. Assuming the production and use of natural resources as central to the reduction imperative, research needs to address institutional gaps; there is no institution in modern society in charge of overseeing the problems that emerge at the society-natural resources interface. Functional differentiation, selfreference, and the large interdependencies that are a consequence of functional differentiation (Luhmann, 1977) undermine society's capacity to manage and facilitate a sustainability transition. New institutions will need to be built, and new forms of collaboration between policy, science and economy are required to grow the capacity of society and its institutions to resonate to the sustainability crisis and start managing it. This will require changes to the way political decisions are made at an international scale and how international trade in commodities (natural resources, products, international recycling) is governed. 
What institutional mechanisms and new institutions would help coordinate decision making and ensure sustainable extraction and use of natural resources? What options exist for strengthening global resource governance and what are their respective merits? How could the establishment of such mechanisms, possibly as polycentric types of governance, be made politically feasible to bring governments and corporations on board and facilitate action at a global scale? What are the economics of the new international division of labour and natural resources? How can producers be encouraged to create new products that rely less on primary natural resources and involve low carbon technologies? How can financial markets contribute to and operate in the context of the reduction imperative? How can investment be targeted to this new direction? How would research integrate local concerns, such as social licence to operate, intercultural dialogue, and participation of civil society? Existing research for earth system governance can be strengthened by a focus on natural resources and physical economy dynamics.

E. Low-resource development pathways. Finding a balance between economic development and the aspirations of millions of people who are currently trapped in poverty but are nevertheless aspiring towards a healthy, well-educated life and access to energy and water as well as modern consumer goods, and avoiding an overshoot in natural resource use, waste amounts and emissions, is at the heart of sustainable development. The post-2015 development agenda of the United Nations and its expression through the SDGs demonstrate powerfully the intention of the global policy community to achieve poverty alleviation, a growing material standard of living, and environmental sustainability. With no known model of a developed country that would be sustainable in the long run, researchers will have to work together with the business and policy communities and citizens to envisage elements of a sustainable society to create strategies, policies and business opportunities for low-resource development pathways. New "business as usual" scenarios should be developed that truly reflect the social and economic costs and environmental disruption if current patterns prevail.

What models of business, urban infrastructure and utility systems exist that do not result in the very high levels of consumption currently required in industrialised countries? How can systems of provision be designed to rely on lower and less constant levels of material and energy throughput? How could mining companies and resource-intensive industries shift from fossil fuels to sustainable extraction of minerals needed based on new business models of creating values for sustainable societies? How could resource-rich developing countries engage in "soft extraction" pathways while also investing in alternative economic pathways to avoid lock-in into inequality and entrenched underdevelopment? What would be the fiscal mechanisms of turning natural endowments into wellbeing for the people, e.g. via green sovereign wealth funds? What do the envisaged changes mean for countries rich in fossil fuel reserves? Which changes at the international level, including changes in trade rules, international financial institutions, and the work done by bilateral and multilateral development partners, would support a shift from conventional natural resourceintensive development to circular, resource-efficient and low-resource development societal patterns and practices? What can be achieved by technology and in which 
areas is social and institutional innovation required? To support the outlined agenda, new narratives must be established to develop scenarios that can be communicated clearly and broadly in international organisations which provide technical support to developing countries.

F. Maintaining wellbeing with reduced throughput. For high-income countries, as well as for wealthy demographics in developing countries, the multifaceted resource crises imply needs for lifestyle changes, which include shifts away from resourceintensive ways of working, earning and spending. There is strong scientific support for these needs, and also growing acceptance in policy circles. However, there is still little consensus on how to bring about and manage such a transformation and on how to maintain and enhance the wellbeing of households and communities in the process. Some observers argue that changes expected to take place over the 21 st century will be profound and can be compared to what happened during the industrial revolution when societies went from an agrarian to an industrial mode of production. Resource constraints, climate change, and demands for ecological justice will not be the only drivers of this transformation but are likely to play important roles. Such a drastic restructuring of society could have serious implications for many people, harming livelihoods and other determinants of wellbeing. There are different views on the extent to which the coming transformation can be purposefully managed, but the research community has an important role in helping society anticipate and prepare for various possible futures, and ideally try to steer away from undesirable outcomes.

The six domains of change we have proposed and the questions we suggest are broad and challenging for research and policy. For many of these questions, current research provides tentative, and partial, answers. In order to facilitate processes of learning among diverse societal actors, the research must be socially engaged, and involve multiple perspectives and disciplines. Modelling and scenario building should play an important roles in exploring alternative futures. In addition, qualitative aspects, such as different cultural principles, should be appropriately reflected in such exercises. In recent years there has been increasing interest in establishing platforms for science-policy interaction, initiatives such as Future Earth and processes associated with the UN system, and the theme of absolute reduction will add an important dimension to their agendas.

\section{Conclusions}

The research presented in this SV demonstrates that the magnitude, scope and urgency of the sustainability challenge require nothing less than profound change of our global "civilisation". A radical transformation of the institutional arrangements and socio-technical systems that must facilitate the pursuit of wellbeing globally is needed to secure the wellbeing of a growing world population. The global economy will need to reduce material and energy throughput, and emissions in absolute terms. There are, however, systemic challenges to achieving absolute reductions some of which have been identified by authors of this special volume, most notably the resource-intensive conventional template for development, macroeconomic structures and trade policies creating burden-shifting and inequality, the resource-efficiency improvements fallacy, and the dominant consumerist culture and lifestyle prevalent in modern society. 
In recent years, methods have advanced in estimating reduction targets for key materials. While establishing concrete targets remains a complex task, most estimations show that globally there is a need to reduce our material footprints and greenhouse gas emissions by as much as $80 \%$ before the middle of this century. This is a huge challenge, and some commentators have expressed that a miracle is required to achieve the changes that are needed. The general consensus is that the use of fossil fuels needs to be halted - almost immediately - with warning that significant amounts of the $\mathrm{CO}_{2}$ emissions allowable by 2035 are already locked-in by existing power plants, factories, buildings, and other infrastructure.

Establishing targets is important to provide orientation towards the changes that are needed. There is, however, an urgent need for the social and cultural sciences to move from theories of socio-cultural change towards a vision of future wellbeing with a reduced natural resource throughput based on sustainable infrastructure - an issue that has been poorly framed as a technical or technological problem. The socio-cultural dimension is crucial for reframing unsustainability as a failure of current technological, economic and political systems. To embark on a development path towards absolute reductions, the social sciences must articulate visions of sustainable civilisations - manifested at the levels of individuals, social groups, and entire societies and pursued through intercultural dialogue to establish alternative narratives to the current socioeconomic paradigm.

Acknowledgements: The authors would like to thank Prof. Donald Huisingh and Dr. Rodrigo Lozano of the Journal of Cleaner Production for their detailed comments on early drafts of this paper. The authors also thank Karin Hosking of CSIRO Australia for language edits.

\section{References}

Adnan, H. (2013). Water, Food, and Energy Nexus in Asia and the Pacific. Bangkok: United Nations Economic and Social Commission for Asia and the Pacific. Retrieved from http://www.unescap.org/sites/default/files/Water-Food-Nexus Report.pdf

Akenji, L. (2014). Consumer scapegoatism and limits to green consumerism. Journal of Cleaner Production, 63, 13-23. http://doi.org/10.1016/j.jclepro.2013.05.022

Akenji, L., \& Bengtsson, M. (2014). Making Sustainable Consumption and Production the Core of Sustainable Development Goals. Sustainability, 6(2), 513-529. http://doi.org/10.3390/su6020513

Andrews-Speed, P., Bleischwitz, R., Boersma, T., Johnson, C., Kemp, G., \& VanDeveer, S. (2014). The Global Resource Nexus and the Struggle for Land, Energy, Food, Water and Minerals. Routledge/Earthscan.

Arvidsson, R., Kushnir, D., Molander, S., \& Sandén, B. A. (2015). Energy and resource use assessment of graphene as a substitute for indium tin oxide in transparent electrodes. Journal of Cleaner Production. http://doi.org/10.1016/j.jclepro.2015.04.076

Bardi, U. (2014). Extracted: how the quest for mineral welath is plundering the planet: a 
report to the Club of Rome. Chelsea Green Publishing.

Bazilian, M., Rogner, H., Howells, M., Hermann, S., Arent, D., Gielen, D., ... Yumkella, K. K. (2011). Considering the energy, water and food nexus: Towards an integrated modelling approach. Clean Cooking Fuels and Technologies in Developing Economies, 39(12), 7896-7906. http://doi.org/10.1016/j.enpol.2011.09.039

BIO Intelligence Service. (2012). Assessment of resource efficiency indicators and targets. Final report prepared for the European Commission, DG Environment. Institute for Social Ecology and Sustainable Europe Research Institute.

Bleischwitz, R. (2012). Towards a resource policy-unleashing productivity dynamics and balancing international distortions. Mineral Economics, 24(2-3), 135-144. http://doi.org/10.1007/s13563-011-0014-5

Bleischwitz, R., Johnson, C., \& Dozler, M. (2014). Re-Assessing resource dependency and criticality. Linking future food and water stress with global resource supply vulnerabilities for foresight analysis. European Journal of Futures Research, 2(1), 1-12.

Bringezu, S. (2015). Possible Target Corridor for Sustainable Use of Global Material Resources. Resources, 4(1), 25-54. http://doi.org/10.3390/resources4010025

Brown, H. S., \& Vergragt, P. J. (2014). From consumerism to wellbeing: Toward a cultural transition? Journal of Cleaner Production. http://doi.org/10.1016/j.jclepro.2015.04.107

Cazcarro, I., Duarte, R., \& Sánchez-Chóliz, J. (2014). Downscaling the grey water footprints of production and consumption. Journal of Cleaner Production, 1-13. http://doi.org/10.1016/j.jclepro.2015.07.113

Chen, P. C., Chiu, M. C., \& Ma, H. wen. (2014). Measuring the reduction limit of repeated recycling - a case study of the paper flow system. Journal of Cleaner Production. http://doi.org/10.1016/j.jclepro.2015.04.023

Cheung, W. W. L., Lam, V. W. Y., Sarmiento, J. L., Kearney, K., Watson, R., Zeller, D., \& Pauly, D. (2010). Large-scale redistribution of maximum fisheries catch potential in the global ocean under climate change. Global Change Biology, 16(1), 24-35. http://doi.org/10.1111/j.1365-2486.2009.01995.x

Dittrich, M., Giljum, S., Lutter, S., \& Polzin, C. (2012). Green economies around the world? Implications of resource use for development and the environment. Vienna: Sustainable Europe Research Institute.

Eriksson, C. (2004). Can green consumerism replace environmental regulation? - A differentiated-products example. Resource and Energy Economics, 26(3), 281-293. http://doi.org/10.1016/j.reseneeco.2003.10.001

Escobar, A. (2006). Difference and Conflict in the Struggle Over Natural Resources: A political ecology framework. Development, 49(3), 6-13.

Friedlingstein, P., Dufresne, J. L., Cox, P. M., \& Rayner, P. (2003). How positive is the feedback between climate change and the carbon cycle? Tellus Series B-Chemical and Physical Meteorology, 55(2), 692-700. http://doi.org/10.1034/j.1600-

0889.2003.01461.x 
Fuchs, D., Di Giulio, A., Glaab, K., Lorek, S., Maniates, M., Princen, T., \& R??pke, I. (2014). Power: The missing element in sustainable consumption and absolute reductions research and action. Journal of Cleaner Production, 1-10. http://doi.org/10.1016/j.jclepro.2015.02.006

Gerland, P., Raftery, a. E., Ev Ikova, H., Li, N., Gu, D., Spoorenberg, T., ... Wilmoth, J. (2014). World population stabilization unlikely this century. Science, 346(6206), 234237.

Giurco, D., McLellan, B., Franks, D. M., Nansai, K., \& Prior, T. (n.d.). Responsible mineral and energy futures: views at the nexus. Journal of Cleaner Production, (0). http://doi.org/10.1016/j.jclepro.2014.05.102

Heimann, M., \& Reichstein, M. (2008). Terrestrial ecosystem carbon dynamics and climate feedbacks. Nature, 451(7176), 289-292. Retrieved from http://www.nature.com/nature/journal/v451/n7176/full/nature06591.html/nhttp://www.n ature.com/nature/journal/v451/n7176/pdf/nature06591.pdf

Hertwich, E. G. (2005). Consumption and the rebound effect: An industrial ecology perspective. Journal of Industrial Ecology, 9(1-2), 85-98. http://doi.org/10.1162/1088198054084635

Hertwich, E. G., van der Voet, E., \& Tukker, A. (2010). Assessing the Environmental Impacts of Consumption and Production. Priority Products and Materials. A Report of the Working Group on the Environmental Impacts of Products and Materials to the International Panel for Sustainable Resource Management.

Hirschnitz-Garbers, M., Tan, A. R., Gradmann, A., \& Srebotnjak, T. (2014). Key drivers for unsustainable resource use - categories, effects and policy pointers. Journal of Cleaner Production, 2(August 2011). http://doi.org/10.1016/j.jclepro.2015.02.038

Hoekstra, A. Y., \& Wiedmann, T. O. (2014). Humanity's unsustainable environmental footprint. Science, 344(6188), 1114-1117.

IEA. (2012). World Energy Outlook 2012. International Energy Agency. http://doi.org/10.1787/20725302

IPCC. (2014). Climate Change 2014: Synthesis Report. Contribution of Working Groups I, II and III to the Fifth Assessment Report of the Intergovernmental Panel on Climate Change. Retrieved from http://www.ipcc.ch/pdf/assessmentreport/ar5/syr/SYR_AR5_FINAL_full.pdf

IPCC, Stocker, T. F., Qin, D., Plattner, G.-K., Tignor, M., Allen, S. K., ... Midgley, P. M. (2013). IPCC, 2013: Climate Change 2013: The Physical Science Basis. Contribution of Working Group I to the Fifth Assessment Report of the Intergovernmental Panel on Climate Change. IPCC, AR5, 1535.

Kalmykova, Y., Rosado, L., \& Patricio, J. (2014). Resource consumption drivers and pathways to reduction: Economy, policy and lifestyle impact on material flows at the national and urban scale. Journal of Cleaner Production, 1-11. http://doi.org/10.1016/j.jclepro.2015.02.027

Knoeri, C., Steinberger, J. K., \& Roelich, K. (2014). End-user centred infrastructure 
operation: Towards integrated end-use service delivery. Journal of Cleaner Production, 1-11. http://doi.org/10.1016/j.jclepro.2015.08.079

Kojima, S., \& Aoki-Suzuki, C. (2015). Efficiency and fairness of resource use: from a planetary boundary perspective. In S. Managi (Ed.), The Economics of Green Growth. London: Routledge.

Kuramochi, T. (2015). Assessment of midterm CO2 emissions reduction potential in the iron and steel industry: A case of Japan. Journal of Cleaner Production, 17. http://doi.org/10.1016/j.jclepro.2015.02.055

Laakso, S., \& Lettenmeier, M. (2014). Household-level transition methodology towards sustainable material footprints. Journal of Cleaner Production, 1-8. http://doi.org/10.1016/j.jclepro.2015.03.009

Le Billon, P. (2001). The political ecology of war: Natural resources and armed conflicts. Political Geography, 20(5), 561-584.

Léautier, F. A., \& Hanson, K. T. (2013). Jobless Economic Growth: Lessons from Africa. The African Capacity Building Foundation.

Lee, B., Preston, F., Kooroshy, J., Bailey, R., Lahn, G., Asia, N., \& Asia, S. (2012). Resources Futures, 249.

Lettenmeier, M., Liedtke, C., \& Rohn, H. (2014). Eight Tons of Material FootprintSuggestion for a Resource Cap for Household Consumption in Finland. Resources, 3(3), 488-515. http://doi.org/10.3390/resources3030488

Luhmann, N. (1977). Differentiation of society. The Canadian Journal of Sociology, 2(1), $29-53$.

Mair, S., Druckman, A., \& Jackson, T. (2014). Global inequities and emissions in Western European textiles and clothing consumption. Journal of Cleaner Production, 1-13. http://doi.org/10.1016/j.jclepro.2015.08.082

Maniatis, P. (2015). Investigating factors influencing consumer decision-making while choosing green products. Journal of Cleaner Production, 1-14. http://doi.org/10.1016/j.jclepro.2015.02.067

Meinshausen, M., Meinshausen, N., Hare, W., Raper, S. C. B., Frieler, K., Knutti, R., ... Allen, M. R. (2009). Greenhouse-gas emission targets for limiting global warming to 2 degrees C. Nature, 458(7242), 1158-1162. Retrieved from http://dx.doi.org/10.1038/nature08017

Millennium Ecosystem Assessment. (2005). Ecosystems and Human Well-being: Synthesis. A Report of the Millennium Ecosystem Assessment. Ecosystems (Vol. 5). World Resources Institute. Retrieved from http://www.who.int/entity/globalchange/ecosystems/ecosys.pdflnhttp://www.loc.gov/cat dir/toc/ecip0512/2005013229.html

Miller, S. A., Billington, S. L., \& Lepech, M. D. (2015). Influence of carbon feedstock on potentially net beneficial environmental impacts of bio-based composites. Journal of Cleaner Production, 1-13. http://doi.org/10.1016/j.jclepro.2015.11.047 
Mohd Suki, N. (2015). Consumer environmental concern and green product purchase in Malaysia: structural effects of consumption values. Journal of Cleaner Production, 111. http://doi.org/10.1016/j.jclepro.2015.09.087

Nunes, B., Alamino, R. C., Shaw, D., \& Bennett, D. (2014). Modelling sustainability performance to achieve absolute reductions in socio-ecological systems. Journal of Cleaner Production, 1-13. http://doi.org/10.1016/j.jclepro.2015.08.037

Paloheimo, H., Lettenmeier, M., \& Waris, H. (2014). Transport reduction by crowdsourced deliveries - a library case in Finland. Journal of Cleaner Production, 1-12. http://doi.org/10.1016/j.jclepro.2015.04.103

Pettersen, I. N. (2014). Fostering absolute reductions in resource use: The potential role and feasibility of practice-oriented design. Journal of Cleaner Production, 1-14. http://doi.org/10.1016/j.jclepro.2015.02.005

Pfister, S., \& Hellweg, S. (2009). The water "shoesize" vs. footprint of bioenergy. Proceedings of the National Academy of Sciences of the United States of America, 106(35), E93-4. http://doi.org/10.1073/pnas.0908069106

Pirani, S. I., \& Arafat, H. A. (2015). Reduction of food waste generation in the hospitality industry. Journal of Cleaner Production. http://doi.org/10.1016/j.jclepro.2015.07.146

Ridoutt, B. G., \& Huang, J. (2012). Environmental relevance--the key to understanding water footprints. Proceedings of the National Academy of Sciences of the United States of America, 109(22), E1424; author reply E1425. http://doi.org/10.1073/pnas.1203809109

Roberts, C. M., Hawkins, J. P., \& Gell, F. R. (2005). The role of marine reserves in achieving sustainable fisheries. Philosophical Transactions of the Royal Society of London. Series B, Biological Sciences, 360(1453), 123-32. http://doi.org/10.1098/rstb.2004.1578

Rockström, J., Steffen, W., Noone, K., Persson, A., Chapin, F. S., Lambin, E. F., ... Foley, J. A. (2009). A safe operating space for humanity. Nature, 461(7263), 472-475. Retrieved from http://dx.doi.org/10.1038/461472a

Rockström, J., Steffen, W., Noone, K., Persson, Å., Chapin, F. S., Lambin, E. F., ... Joachim, H. (2009). Planetary Boundaries : Exploring the safe operating space for humanity. Ecology and Society, (September), 1-36.

Rogelj, J., Schaeffer, M., Friedlingstein, P., Gillett, N. P., van Vuuren, D. P., Riahi, K., ... Knutti, R. (2016). Differences between carbon budget estimates unravelled. Nature Climate Change, 6(3), 245-252. Retrieved from http://dx.doi.org/10.1038/nclimate2868

Rothman, D. S., van Bers, C., Bakkes, J., \& Pahl-Wostl, C. (2009). How to make global assessments more effective: lessons from the assessment community. Current Opinion in Environmental Sustainability, 1(2), 214-218. Retrieved from http://www.sciencedirect.com/science/article/pii/S1877343509000293

Schandl, H., Hardfield-Dodds, S., Wiedmann, T., Geschke, A., Cai, Y., West, J., ... Owen, A. (2015). Decoupling global environmental pressure and economic growth: scenarios for energy use, materials use and carbon emissions. Journal of Cleaner Production, 1-12. http://doi.org/10.1016/j.jclepro.2015.06.100

Scheffer, M., Brovkin, V., \& Cox, P. M. (2006). Positive feedback between global warming 
and atmospheric $\mathrm{CO} 2$ concentration inferred from past climate change. Geophysical Research Letters, 33(October 2005), L10702. http://doi.org/10.1029/2005GL025044

Schuur, E. A. G., McGuire, A. D., Grosse, G., Harden, J. W., Hayes, D. J., Hugelius, G., ... Kuhry, P. (2015). Climate change and the permafrost carbon feedback. Nature, 520(January 2016), 171-179.

Seebauer, S., Kulmer, V., Bruckner, M., \& Winkler, E. (2014). Carbon emissions of retail channels: The limits of available policy instruments to achieve absolute reductions. Journal of Cleaner Production. http://doi.org/10.1016/j.jclepro.2015.02.028

Simms, A., Johnson, V., \& Chowla, P. (2010). Growth isn't possible. New Economics Foundation. Retrieved from http://scholar.google.com/scholar?hl=en\&btnG=Search\&q=intitle:Growth + isn $+{ }^{\prime}+\mathrm{t}+$ poss ible\#0

Steffen, W., Richardson, K., Rockstrom, J., Cornell, S. E., Fetzer, I., Bennett, E. M., ... Sorlin, S. (2015). Planetary boundaries: Guiding human development on a changing planet. Science, 347(6223), 1259855-. Retrieved from http://www.sciencemag.org/content/early/2015/01/14/science.1259855.abstractlnhttp://w ww.sciencemag.org/content/347/6223/1259855

Thomas, D. P. (2009). The World Bank: Development, Poverty, Hegemony. Review of African Political Economy, 36(121), 467-468.

Tukker, A., Bulavskaya, T., Giljum, S., de Koning, A., Lutter, S., Simas, M., ... Wood, R. (2014). The Global Resource Footprint of Nations. Carbon, water, land and materials embodied in trade and final consumption calculated with EXIOBASE 2.1. Leiden/Delft/Vienna/Trondheim.

UN Secretary General. (2014). The Road to Dignity by 2030: Ending Poverty, Transforming All Lives and Protecting the Planet. Synthesis Report of the Secretary-General On the Post-2015 Agenda (advance unedited). New York.

UNEP. (2007). GEO 4: Environment for development. Retrieved from http://www.unep.org/geo/GEO4/report/GEO-4_Report_Full_en.pdf

UNEP. (2011). Decoupling Natural Resource Use and Environmental Impacts from Economic Growth. A Report of the Working Group on Decoupling to the International Resource Panel. In United Nations Environment Programme.

UNEP. (2012). GEO 5: Environment for the future we want. Retrieved from http://www.unep.org/geo/pdfs/geo5/GEO5_report_full_en.pdf

UNEP. (2014). The Emissions Gap Report 2014: A UNEP synthesis Report. Unep. Nairobi: United Nations Environment Programme. Retrieved from http://www.unep.org/pdf/SEI.pdf

United Nations Economic and Social Commission for Asia and the Pacific (UNESCAP). Water, Food, and Energy Nexus in Asia and the Pacific - Discussion paper, United Nations Publication 72 (2013). Retrieved from http://www.unescap.org/sites/default/files/Water-Food-Nexus Report.pdf

Van Ewijk, S., \& Stegemann, J. A. (2014). Limitations of the waste hierarchy for achieving 
absolute reductions in material throughput. Journal of Cleaner Production, 1-7. http://doi.org/10.1016/j.jclepro.2014.11.051

van Vuuren, D. P., \& Faber, A. (2009). Growing within Limits: A Report to the Global Assembly 2009 of the Club of Rome. Bilthoven.

Vīgants, E., Blumberga, A., Timma, L., Ījabs, I., \& Blumberga, D. (2015). The dynamics of technological substitution: the case of eco-innovation diffusion of surface cleaning products. Journal of Cleaner Production, 1-10. http://doi.org/10.1016/j.jclepro.2015.10.007

WEF. (2011). Global Risks 2011 (11th ed.). Geneva: World Economic Forum.

Welfens, M. J., Nordmann, J., \& Seibt, A. (2015). Drivers and barriers to return and recycling of mobile phones. Case studies of communication and collection campaigns. Journal of Cleaner Production. http://doi.org/10.1016/j.jclepro.2015.11.082

WHO, Watts, N., Adger, W. N., Agnolucci, P., Blackstock, J., Byass, P., ... Yach, D. (2015). Reducing Global Health Risks Through Mitigation of Short-Lived Climate Pollutants. Scoping Report For Policy-makers. The Lancet, 6736(15), 53. http://doi.org/10.1016/S0140-6736(15)60901-1

Wijkman, A., \& Rockström, J. (2012). Bankrupting Nature: Denying Our Planetary Boundaries: a report to the Club of Rome. New York: Routledge.

World Health Organization. (2014). Burden of disease from Ambient Air Pollution for 2012.

WRG. (2009). Charting Our Water Future. Water, June(3), 1-32. Retrieved from http://www.mckinsey.com/App_Media/Reports/Water/Charting_Our_Water_Future_Ful 1_Report_001.pdf\nhttp://scholar.google.com/scholar?hl=en\&btnG=Search\&q=intitle:C harting+Our+Water+Future\#1 \nhttp://www.mckinsey.com/App_Media/Reports/Water/ Charting_Our_Water_Fu 